\title{
Efeito da Densidade de Povoamento na Produtividade Final em Carpas (Cyprinus carpio var specularis) em Fase de Engorda, durante o Verão
}

\author{
Álvaro Graeff ${ }^{1}$, Evaldo Nazareno Pruner ${ }^{2}$
}

RESUMO - O objetivo desta pesquisa foi estudar o efeito da densidade de povoamento na produtividade final, em carpas na fase de engorda, no período de verão. O delineamento foi inteiramente casualizado com três tratamentos $\left(1 ; 0,5\right.$; e 0,33 peixes $\left./ \mathrm{m}^{2}\right)$ e três repetições. Os peixes foram estocados com peso e comprimento médios de 2,40 g e 5,35; 5,40 e 5,39 cm, respectivamente, nos tratamentos 1,2 e 3 , com 45 dias de idade. As dietas foram formuladas com $27 \% \mathrm{~PB}$ e $2925 \mathrm{kcal} / \mathrm{kg}$ de ração, sendo fornecidas diariamente, na quantidade de $3 \%$ do peso vivo. O comportamento dos tratamentos foi estudado por intermédio da análise de regressão. Os resultados para o comprimento e peso dos peixes foram 25,68; 28,66; e 31,21 cm e 255,00; 424,00; e 519,66 g, respectivamente. Os tratamentos 1 e 3 apresentaram modelo de regressão linear diferente do tratamento 2, que apresentou modelo quadrático. Na biomassa total, os resultados foram 1881; 1512; e $1302 \mathrm{~kg} / \mathrm{ha} /$ período e os modelos de regressão significativos para os tratamentos 1e 3 foram lineares e para o tratamento 2 quadrático. A conversão alimentar apresentou modelo de regressão linear para todos tratamentos. Em condições similares, podem-se recomendar todas densidades sugeridas, com base na produção final e sobrevivência.

Palavras-chave: Cyprinus carpio, densidade, engorda, verão

\section{Effect of Population Density on the Productivity of Carp (Cyprinus carpio var specularis), in the Fattening Stage, During the Summer}

\begin{abstract}
This study aimed to evaluate impact of stocking density on final productivity in the production of mirror common carp in fattening stage, during the summer. A completely randomized design with three treatments $\left(1, .5, .33\right.$ fishes $\left./ \mathrm{m}^{2}\right)$ and three replicates was used. The fish were stocked with an average weight of $2.40 \mathrm{~g}$ and average length of $5.35,5.40$ and $5.39 \mathrm{~cm}$, respectively, in the treatments 1, 2 and 3, with 45 days of age. The diets were formulated with $27 \% \mathrm{CP}$ and $2925 \mathrm{kcal} / \mathrm{kg}$ of diet and supplied daily at a rate of $3 \%$ of body weight. Regression analysis was used to evaluate the behavior of each treatment. For the fish lengths, the results were $25.68,28.66$ and $31.21 \mathrm{~cm}$, respectively. For the fish weights, the results were 255.00, 424.00, and $519.66 \mathrm{~g}$. The treatments 1 and 3 showed a linear regression model, different from the treatment 2 , that showed quadratic model. In the total biomass, the results were 1881,1512 and $1302 \mathrm{~kg} / \mathrm{ha}$ •period and the significant regression model were linear for treatments 1 and 3 and quadratic for treatment 2. The feed: gain showed a linear regression model for all treatments. In similar condition, it could be recommended all suggested densities, based on the final production and survival.
\end{abstract}

Key Words: Cyprinus carpio, density, fattening, summer

\section{Introdução}

As carpas encontram-se hoje com uma área de criação amplamente distribuída no mundo inteiro, devido à sua rusticidade, ao rápido crescimento, ao regime alimentar onívoro (detritófago), à propagação natural em tanques e viveiros, além de outras qualidades desejáveis.

Segundo SILVA et al. (1983a), já se cultivam carpas há mais de 3000 anos, na Ásia e no Oriente Médio, e há cerca de 600 anos na Europa.

No Brasil, a carpa foi primeiramente introduzida em 1882 (NOMURA, 1984), sendo trazida dos Estados Unidos para o Rio de Janeiro (SILVA, 1983a).
Em São Paulo, chegou em 1904, segundo MAKINOUCHI (1980), o qual indica que novas amostras da Alemanha foram enviadas para o município de Piracicaba, transferindo-se, em 1932, para Pindamonhangaba. No ano de 1934, implantou-se o sistema de produção de alevinos de carpa e sua distribuição para interessados, dando início à criação da carpa em água parada no Brasil.

A criação de carpas em tanques constitui-se em um método promissor e eficaz para a produção de peixes. O emprego de rações balanceadas possibilita elevada densidade de estocagem, permitindo melhores técnicas de criação intensiva de peixes (SZUMIEC, 1979).

\footnotetext{
${ }^{1}$ Médico Veterinário CRMV SC-0704 - Pesquisador em Nutrição/EPAGRI - Estação de Piscicultura. E.mail: galvaro@unc-cdr.rct-sc.br ${ }^{2}$ Médico Veterinário CRMV SC-0401 - Pesquisador em Reprodução/EPAGRI - C.P. 591 CEP: 89500-000 - Caçador - SC.
} 
HENAO e BOLAÑOS M. (1982) e CORREDOR e HENAO (1982) criaram a carpa-espelho em mono e policultivo com tilápia do Nilo, sendo os peixes alimentados com concentrados para galináceos, tendo bons resultados.

O objetivo deste trabalho foi divulgar os resultados do cultivo da carpa-espelho, em monocultivo, em várias densidades na fase de engorda, no período de verão, com ração, adubação química e orgânica, em continuidade aos trabalhos já realizados por GRAEFF (1997), visando obter informações sobre crescimento em peso e comprimento, sobrevivência, biomassa total, ganho de peso, conversão alimentar.

\section{Material e Métodos}

O experimento foi realizado no período de 22 de novembro de 1995 a 21 de março de 1996, no Posto de Piscicultura de Videira, Santa Catarina, sendo utilizados nove viveiros de terra com áreas diferenciadas, conforme Tabela 3, e profundidade média de $0,80 \mathrm{~m}$. Todos eram abastecidos a partir de um canal de derivação, que provém de um tanque de abastecimento, com escoamento feito individualmente por um sistema de PVC, chamado "cotovelo móvel”, com água corrente. O delineamento experimental foi inteiramente casualizado com três tratamentos e três repetições. Os tratamentos consistiram de 1; 0,5 ; e 0,33 peixes $/ \mathrm{m}^{2}$ respectivamente, em cada viveiro, escolhidos ao acaso com peso médio de $2,40 \mathrm{~g} \mathrm{e}$ comprimento médio de 5,$35 ; 5,40$; e $5,39 \mathrm{~cm}$, respectivamente, e idade de 45 dias. Foram obtidas, por meio de análise de regressão, as equações que descrevem o comportamento de peso individual médio (g), biomassa total (g), comprimento (cm) e conversão alimentar dos peixes, ao longo das avaliações.

A dieta foi formulada com produtos facilmente encontrados na região, dentro dos critérios, para a espécie e o sistema de produção (NATIONAL RESEARCH COUNCIL - NRC, 1993), conforme Tabela 1. A ração foi composta de $27 \%$ PB e $2.925 \mathrm{kcal} / \mathrm{kg}$ de ração, duas vezes ao dia, na proporção de $3 \%$ do peso vivo, sendo aferida novamente a cada 30 dias no momento da ictiometria, em que se mensuraram $30 \%$ dos peixes de todas repetições.

A temperatura da água foi medida diariamente às $9 \mathrm{~h}$, quando os peixes receberam a primeira parte do arraçoamento diário, sendo também medidas a temperatura ambiente e a umidade relativa do ar, por um aparelho de cordas marca Wilh-Lambrech/Gmbh Gottingern, e a transparência, por intermédio do disco
Tabela 1 - Fórmula e composição bromotológica

Table 1 - Formula and chemical composition

\begin{tabular}{lcc}
\hline $\begin{array}{l}\text { Ingredientes } \\
\text { Ingredients }\end{array}$ & $\begin{array}{c}\text { PB\% } \\
C P\end{array}$ & $\%$ \\
\hline $\begin{array}{l}\text { Ração comercial } \\
\text { Commercial diet }\end{array}$ & 50 & 37,5 \\
$\begin{array}{l}\text { Farelo de trigo } \\
\text { Wheat meal }\end{array}$ & 21 & 21,7 \\
$\begin{array}{l}\text { Farelo de milho } \\
\text { Ground corn }\end{array}$ & & 39,4 \\
$\begin{array}{l}\text { Oleo vegetal } \\
\text { Vegetable oil }\end{array}$ & 9 & 1,4 \\
$\begin{array}{l}\text { Proteína bruta } \\
\text { Crude protein }\end{array}$ & - & 27 \\
$\begin{array}{l}\text { Energia metabolizável (kcal/kg) } \\
\text { Metabolizable energy }\end{array}$ & & 2925 \\
\hline
\end{tabular}

de Secchi, sempre no dia das avaliações mensais.

Oxigênio dissolvido, pH, gás carbônico, dureza, alcalinidade e amônia foram obtidos por intermédio de um kit de análises de campo de marca Alfaquímica.

Para obtençãodo peso individual, foram amostrados, em cada avaliação, $30 \%$ dos peixes ao acaso e pesados em uma balança eletrônica com precisão de $0,01 \mathrm{~g}$, marca Mettler 4400-Delta Ranger, e capturados com uma rede de arrasto. Para a medida do comprimento, foi utilizada uma régua milimetrada

A cada 15 dias, foi utilizado adubo orgânico de suínos na dose de $4000 \mathrm{~kg} / \mathrm{ha}$, com $25 \%$ de matéria seca e, na outra quinzena, intercalada, $60 \mathrm{~kg}$ de uréia comercial com $45 \%$ de $\mathrm{N}$ mais superfosfato triplo na dose de $40 \mathrm{~kg} / \mathrm{ha}$ com $46 \%$ de $\mathrm{P}_{2} \mathrm{O}_{5}$.

Ao final do experimento, avaliaram-se todos os peixes e realizou-se análise quantitativa, compreendendo sobrevivência, peso médio e biomassa total e conversão alimentar.

\section{Resultados e Discussão}

A temperatura da água, durante o período experimental (Figura 1), manteve-se entre 21,5 e $25,1^{\circ} \mathrm{C}$, ficando a média do período em $23,2^{\circ} \mathrm{C}$, bem próximo do relato de ARRIGNON (1979), MAKINOUCHI (1980) e CASTAGNOLLI (1986), os quais afirmaram que o melhor crescimento das carpas ocorre entre $24 \mathrm{e} 28^{\circ} \mathrm{C}$, fato que não prejudicou o crescimento dos peixes, conforme demonstra as Tabelas 2 e 4 . A transparência (Figura 2) manteve-se em $40 \mathrm{~cm}$, medida recomendável para a piscicultura, conforme WOYNAROVICH (1985), sendo confirmado pela coloração esverdeada da água, indicando bastante 
Rev. bras. zootec.

plâncton em suspensão, o que, por conseguinte, aumenta a produtividade natural do viveiro.

A temperatura média mensal ambiente, no período de dezembro a março, foi, respectivamente, de 21,5; 21,$5 ; 22,2$; e $21,8^{\circ} \mathrm{C}$, ligeiramente acima do normal para a região (Estação Experimental de Videira).

O pH (Figura 2) oscilou entre 6,69 e 8,17, sendo considerado levemente alcalino(CASTAGNOLLI,1992; HUET, 1978) e ótimo para produção primária.

O oxigênio dissolvido (Figura 2 ) sempre oscilou entre 4,0 e $8,0 \mathrm{mg} / \mathrm{litro}$, amplitude considerada razoável pelo percentual médio de $60 \%$ de saturação, conforme resultados de REID e WOOD (1976), ARRIGNON (1979) e CASTAGNOLLI (1992), declinando na última quinzena do experimento para $2,4 \mathrm{mg} / \mathrm{litro}$, o que não é normal em meio natural.

O nível de gás carbônico (Figura 2), em função da adubação orgânica, iniciou muito alto, acima de $10 \mathrm{mg} / \mathrm{litro}$, o que é muito crítico, mas decresceu com o desenvolvimento do experimento, até atingir nível de 2,0 mg/litro, o qual, segundo ARRIGNON (1979), é considerado normal.

A alcalinidade (Figura 2), durante todo experimento, esteve abaixo de $30 \mathrm{mg} /$ litro, o que indicaria necessidade de calagem (BOYD, 1997), para responder mais favoravelmente às adubações feitas, mas apesar disto não trouxe oscilações no $\mathrm{pH}$ e nem alterações comportamentais nos peixes.

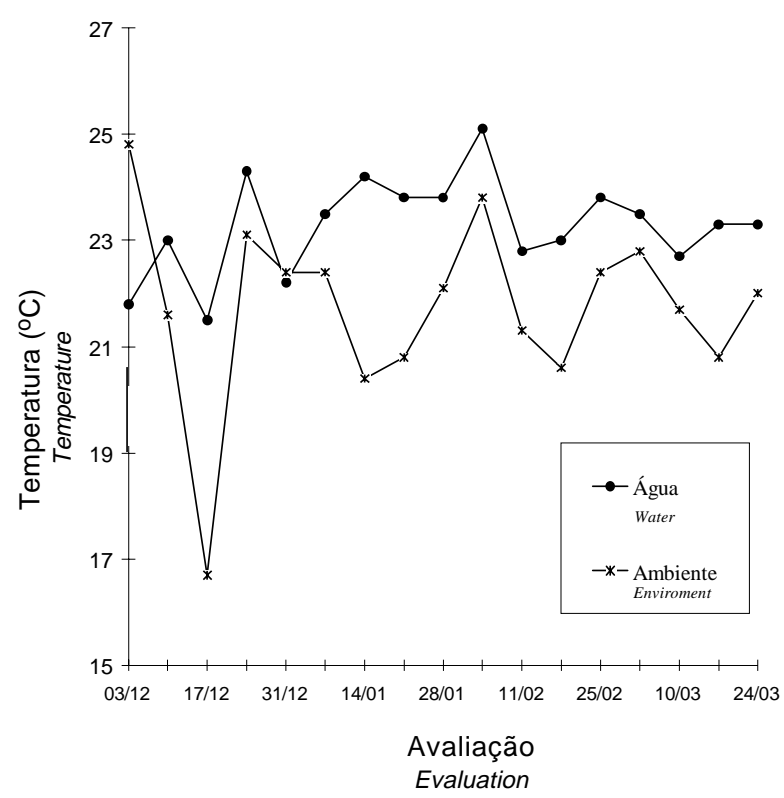

Figura 1 - Temperatura média da água e do meio ambiente no decorrer do experimento.

Figure 1 - Average water and environment temperature during the experiment.
641

A dureza (Figura 2), durante o experimento, oscilou entre 26 e $48 \mathrm{mg} / \mathrm{litro}$, encontrando-se, portanto, sempre abaixo do recomendável por BOYD (1997), de 50 a $80 \mathrm{mg} /$ litro de $\mathrm{CaCO}_{3}$.

A amônia (Figura 2) sempre esteve em níveis acima do normal (0,7 a $1,1 \mathrm{mg} /$ litro), mas abaixo do recomendado por LUKOWICZ (1982) e ORDOG (1988), em experimentos de tolerância à amônia livre, para a carpa comum (Cyprinus carpio L.)

A sobrevivência obtida nos tratamentos 1,2 e 3 foi, em média, 73,78; 71,35; e 75,21\%, respectivamente (Tabela 3), estando dentro do esperado, com povoamento de alevinos de $2,4 \mathrm{~g}$ de peso para a região, passível de perda por ataque de predadores.

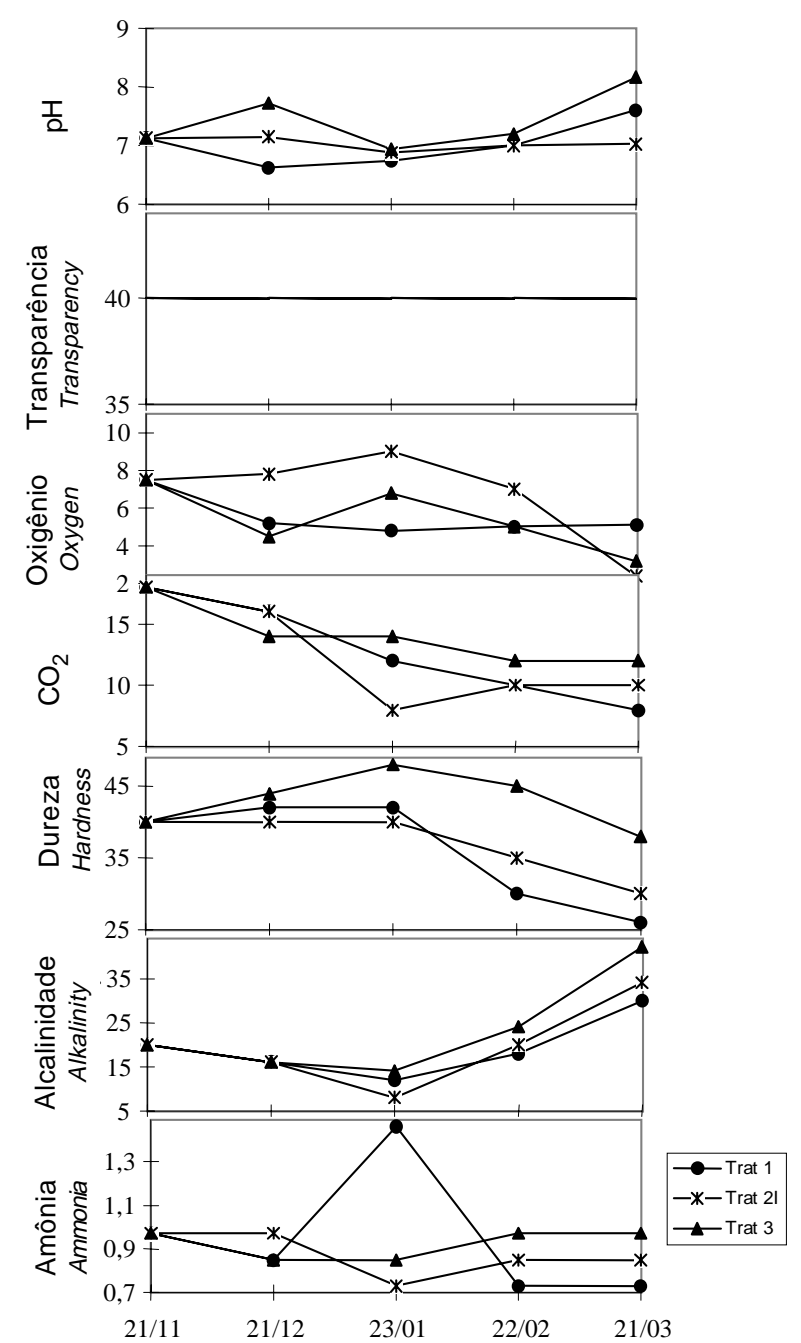

Figura 2 - pH, transparência, oxigênio, $\mathrm{CO}_{2}$, dureza, alcalinidade e concentração de amônia da água, em três densidades de povoamento, no verão

Figure 2 - $\mathrm{pH}$, transparency, oxygen, $\mathrm{CO}_{2}$, hardness, alkalinity and ammonia concentration of water, in three treatments, during the summer. 
Tabela 2 - Comprimento total e peso médio de carpa (Cyprinus carpio - var. specularis) nos três tratamentos na fase de engorda - verão

Table 2 - Total lenght and average weight of carp (Ciprinus carpio var. specularis) in the three treatments in the finishing phase - summer

\begin{tabular}{lrrrrrrr}
\hline & \multicolumn{3}{c}{$\begin{array}{c}\text { Comprimento }(\mathrm{cm}) \\
\text { Lenght }\end{array}$} & & \multicolumn{3}{c}{$\begin{array}{c}\text { Peso }(\mathrm{g}) \\
\text { Weight }\end{array}$} \\
\cline { 2 - 4 } \cline { 7 - 8 } Date & $\mathrm{T} 1$ & $\mathrm{~T} 2$ & $\mathrm{~T} 3$ & & $\mathrm{~T} 1$ & $\mathrm{~T} 2$ & $\mathrm{~T} 3$ \\
\hline $22 / 11$ & 5,37 & 5,40 & 5,39 & & 2,40 & 2,40 & 2,40 \\
$21 / 12$ & 13,37 & 14,84 & 15,85 & & 42,43 & 67,08 & 82,97 \\
$23 / 01$ & 19,07 & 21,84 & 23,76 & & 121,99 & 168,82 & 243,87 \\
$22 / 02$ & 22,00 & 25,20 & 27,80 & & 181,96 & 282,06 & 376,13 \\
$21 / 03$ & 25,68 & 28,66 & 31,21 & & 255,00 & 424,00 & 519,66 \\
\hline
\end{tabular}

* Tratamento 1: 1,00 peixe $/ \mathrm{m}^{2}$ (treatment 1: $1.00 \mathrm{fish} / \mathrm{m}^{2}$ ).

Tratamento 2: 0,50 peixe $/ \mathrm{m}^{2}$ (treatment 2: $2.00 \mathrm{fish} / \mathrm{m}^{2}$ ).

Tratamento 3: 0,33 peixe $/ \mathrm{m}^{2}$ (treatment 3: $3.00 \mathrm{fish} / \mathrm{m}^{2}$ ).

Tabela 3 - Taxa sobrevivência de carpas espelho em fase de engorda - verão Table 3 - Survival rate of common mirror carps in the finishing phase - summer

\begin{tabular}{|c|c|c|c|c|c|c|}
\hline \multirow[t]{2}{*}{$\begin{array}{l}\text { Trat. } \\
\text { Treat }\end{array}$} & \multirow{2}{*}{$\begin{array}{c}\text { Densidade } \\
\text { Density } \\
\left(\mathrm{m}^{2)}\right.\end{array}$} & \multicolumn{2}{|c|}{$\begin{array}{c}\text { № Peixes } \\
\text { Number of fishes }\end{array}$} & \multirow[t]{2}{*}{$\begin{array}{l}\text { Sobrevivência } \\
\text { Survival rate }(\%)\end{array}$} & \multirow{2}{*}{$\begin{array}{l}\text { Sobrevivência } \\
\text { média }(\%) \\
\text { Survival rate } \\
\text { mean }\end{array}$} & \multirow{2}{*}{$\begin{array}{l}\text { Sobrevivência } \\
\text { peixe/tratamento } \\
\text { Fish survival/ } \\
\text { treatment }\end{array}$} \\
\hline & & $\begin{array}{l}\text { Início } \\
\text { Initial } \\
\end{array}$ & $\begin{array}{c}\text { Final } \\
\text { Final }\end{array}$ & & & \\
\hline 1 & $\begin{array}{l}1,00 \\
1,00 \\
1,00\end{array}$ & $\begin{array}{l}155 \\
150 \\
210 \\
\end{array}$ & $\begin{array}{l}109 \\
103 \\
168 \\
\end{array}$ & $\begin{array}{l}70,32 \\
68,66 \\
80,00 \\
\end{array}$ & 73,78 & 380 \\
\hline 2 & $\begin{array}{l}0,50 \\
0,50 \\
0,50\end{array}$ & $\begin{array}{r}75 \\
143 \\
180\end{array}$ & $\begin{array}{c}49 \\
105 \\
130\end{array}$ & $\begin{array}{l}65,33 \\
73,42 \\
72,22\end{array}$ & 71,35 & 284 \\
\hline 3 & $\begin{array}{l}0,33 \\
0,33 \\
0,33 \\
\end{array}$ & $\begin{array}{r}54 \\
54 \\
122 \\
\end{array}$ & $\begin{array}{l}41 \\
44 \\
88 \\
\end{array}$ & $\begin{array}{l}75,92 \\
81,48 \\
72,13 \\
\end{array}$ & 75,21 & 173 \\
\hline
\end{tabular}

O incremento do peso médio dos peixes, durante a execução do experimento, apresentou como resultado finais 255,$00 ; 424,00 ;$ e 519,66 g, respectivamente, nos tratamentos 1,2 e 3 e está indicado nas Tabelas 2 e 4. As análises de regressão para peso médio do peixe, em função das avaliações para cada tratamento, estão apresentadas na Figura 3. Observa-se que os tratamentos 1 e 3 apresentaram um modelo linear e o tratamento 3, maior incremento de peso, ao longo das avaliações, em relação aos demais tratamentos. O tratamento 2 teve um modelo de regressão quadrático.

Os resultados para o comprimento final são 25,68; 28,66; e 31,21, respectivamente, para os tratamentos 1, 2 e 3. Na análise das equações das regressões, para a variável comprimento (Figura 4), o modelo linear foi o que melhor se adequou para o tratamento 1 e o quadrático, para os tratamentos 2 e 3, obtendo-se o melhor resultado de comprimento no tratamento 3.

As médias dos tratamentos nas avaliações para

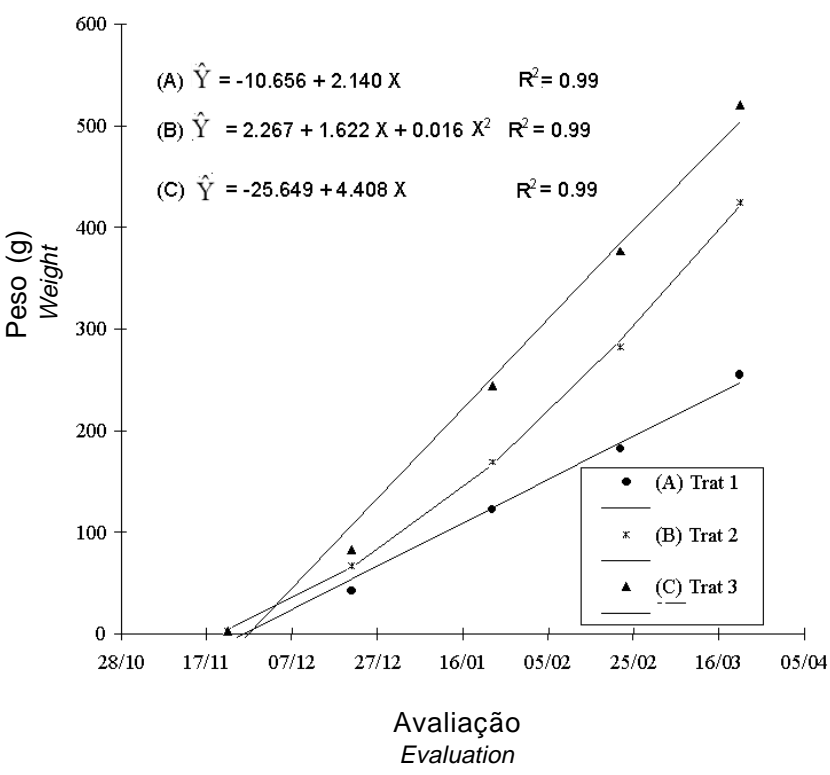

Figura 3 - Regressão para peso, em função das diversas avaliações em três densidades, no verão.

Figure 3 - Regression for weight, in function of several evaluations on the three densities, in summer. 
biomassa total constam da Tabela 4, na qual se constatam os resultados finais de 1881, $1512 \mathrm{e}$ $1302 \mathrm{~kg} /$ tratamento/período, respectivamente, para os tratamentos 1, 2 e 3. O modelo de regressão linear (Figura 5) foi o que melhor se adequou aos tratamentos 1 e 3 e o quadrático, ao tratamento 2 , o qual apresentou maior incremento nas últimas avaliações. Nesse caso, o tratamento 3 apresentou menor acréscimo de peso ao longo das avaliações em relação aos tratamentos 1 e 2. Analisando-se o aproveitamento dos pesos individuais (Tabela 2), pode-se inferir que, dependendo do destino dado ao peixe, os maiores para filés ou in natura e os menores para fishburgers, qualquer tratamento mostraria resultado significativo.

A conversão alimentar nos tratamentos 1,2 e 3 (Tabela 4) foi, respectivamente, 1,34; 1,05; e 1,23. Comparando os resultados dos tratamentos desta pesquisa com aqueles encontrado por SILVA (1984) e SILVA (1983), 1,3 e 1,5, respectivamente, nota-se nítida vantagem para este trabalho, já que foi obtida menor conversão alimentar para o mesmo período de 90 dias, constatando-se que a ração utilizada (Tabela 1) é a mais adequada, para esta fase de engorda das carpas, em complementação ao alimento natural. $\mathrm{Na}$ Figura 6, está a curva de regressão para cada tratamento ao longo das avaliações, em que o modelo de regressão foi linear para todos tratamentos.

Quanto ao uso de adubação química na dosagem de $60 \mathrm{~kg}$ uréia, mais $40 \mathrm{~kg}$ superfosfato triplo/hectare/mês e adubação orgânica na dosagem de $4000 \mathrm{~kg}$ de esterco suíno/hectare/mês (25\% MS), intercalado em 15 em 15 dias (Tabela 5), o resultado foi eficaz para o aumento da biomassa total em complementação à ração oferecida. Na medida em que o experimento desenvolvia, a transparência mantinha-se em $40 \mathrm{~cm}$, a cor da água alterava para esverdeada e a conversão alimentar tornava-se mais eficiente, em função do aumento da produtividade aquática, apesar de o nível de oxigênio dissolvido declinar nos últimos dois meses e a concentração de nitrogênio estar pouco abaixo do normal e o fósforo, pouco acima do preconizado por WOYNAROVICH (1985).

\begin{tabular}{|c|c|c|c|c|c|}
\hline $\begin{array}{l}\text { Tratamento } \\
\text { Treatment }\end{array}$ & $\begin{array}{l}\text { Densidade } \\
\left(\mathrm{m}^{2}\right) \\
\text { Density } / m^{2}\end{array}$ & $\begin{array}{c}\text { Peso médio } \\
\text { inicial (g) } \\
\text { Average } \\
\text { initial } \\
\text { weight }\end{array}$ & $\begin{array}{c}\text { Peso médio } \\
\text { final (g) } \\
\text { Average } \\
\text { final } \\
\text { weight }\end{array}$ & $\begin{array}{c}\text { Biomassa total }(\mathrm{kg}) / \\
\text { período } \\
\text { Total biomass } / \\
\text { period }\end{array}$ & $\begin{array}{c}\text { Conversão } \\
\text { alimentar } \\
\text { Feed/gain ratio }\end{array}$ \\
\hline 1 & 1,00 & 2,40 & 255,00 & 1881 & $1,34: 1$ \\
\hline 2 & 0,50 & 2,40 & 424,00 & 1512 & $1,05: 1$ \\
\hline 3 & 0,33 & 2,40 & 519,66 & 1302 & $1,23: 1$ \\
\hline
\end{tabular}

Tabela 5 - Quantidade de adubos adicionais nos tratamentos

Table 5 - Amount of fertilizer added in the treatments

\begin{tabular}{|c|c|c|c|c|}
\hline $\begin{array}{l}\text { Data } \\
\text { Date }\end{array}$ & $\begin{array}{l}\text { Tratamento } \\
\text { Treatment }\end{array}$ & $\begin{array}{l}\text { Adubo/Suíno (g) } \\
\text { Slurry/Swine }\end{array}$ & $\begin{array}{c}\text { Quantidade } / \mathrm{m}^{2} \\
\text { Úreia }(\mathrm{g}) \\
\text { Amount } / \mathrm{m}^{2} \text { Urea }\end{array}$ & $\begin{array}{l}\text { Supertriplo } \\
\text { Superphosphate } \\
\text { triple }\end{array}$ \\
\hline $22 / 11$ & $1,2,3$ & 400 & & \\
\hline $07 / 12$ & $1,2,3$ & & 6,0 & 4,0 \\
\hline $22 / 12$ & $1,2,3$ & 400 & & \\
\hline $06 / 01$ & $1,2,3$ & & 6,0 & 4,0 \\
\hline $24 / 01$ & $1,2,3$ & 400 & & \\
\hline $05 / 02$ & $1,2,3$ & & 6,0 & 4,0 \\
\hline $21 / 02$ & $1,2,3$ & 400 & & \\
\hline $06 / 03$ & $1,2,3$ & & 6,0 & 4,0 \\
\hline
\end{tabular}




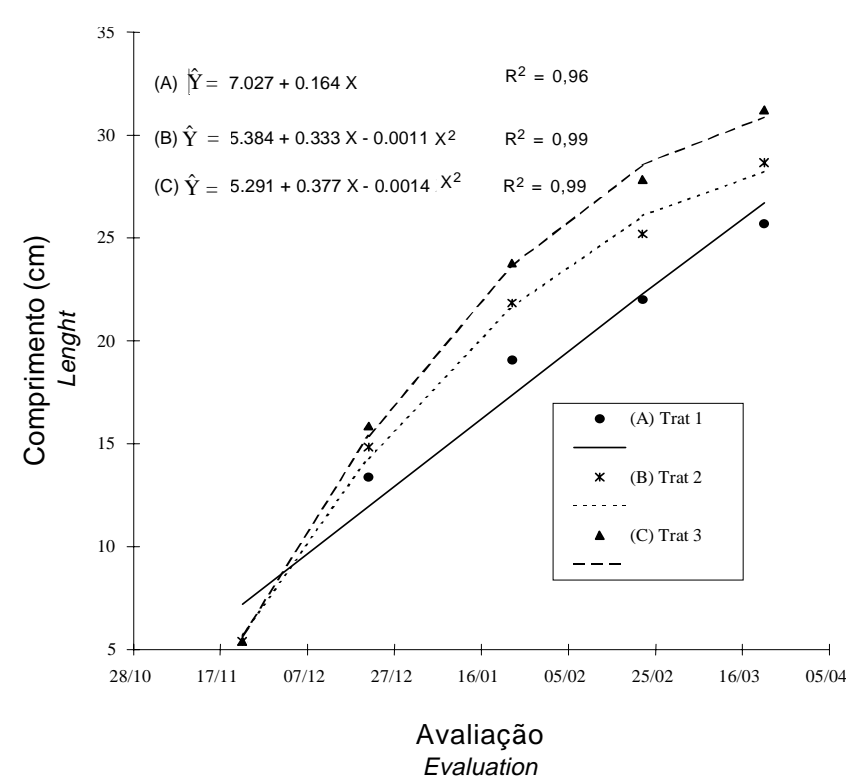

Figura 4 - Regressão para comprimento, em função das diversas avaliações em três densidades, no verão.

Figure 4 - Regressions for the lenght, in function of several evaluations on the three densities, in summer.

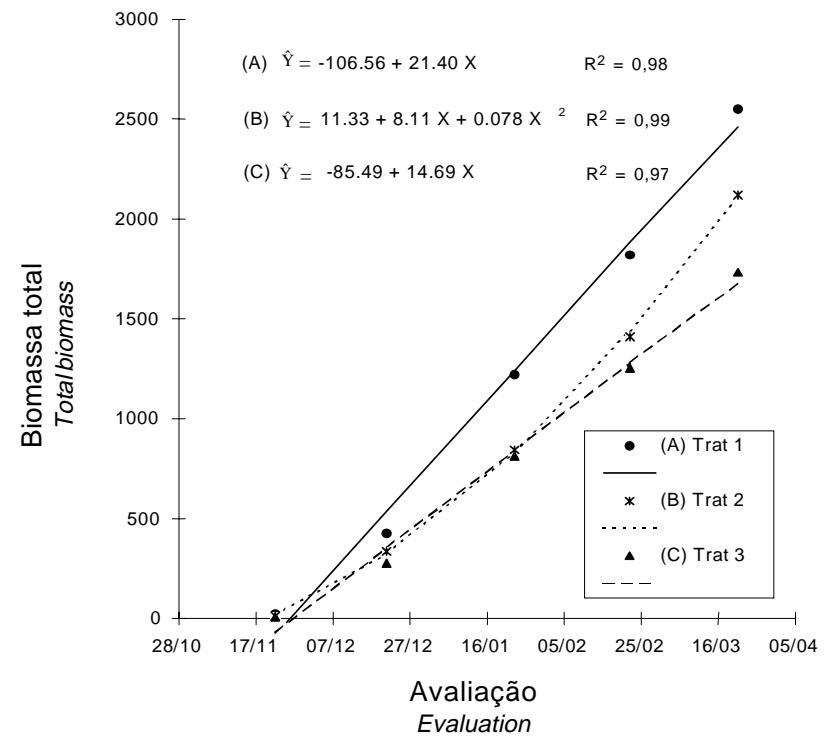

Figura 5 - Regressão para biomassa total, em função das diversas avaliações em três densidades, no verão.

Figure 5 - Regressions for total biomass, in function of several evaluations on the three densities, in summer.

\section{Conclusões}

Quanto maior a densidade de cultivo, maior a biomassa total final.

Quanto menor a densidade de cultivo, maior o peso individual dos peixes.

As adubações química e orgânica utilizadas, nas quantidades ofertadas, foram eficientes.

Recomenda-se que novos experimentos, nesta linha, sejam realizados para confirmação das conclusões acima, visando determinar parâmetros de produção dos viveiros.

\section{Agradecimento}

À Prefeitura Municipal de Videira, por intermédio da Secretaria de Agricultura, a qual colocou o Posto de Piscicultura à nossa disposição, para realização destes experimentos. 


\section{Referências Bibliográficas}

ARRIGNON,I. 1979. Ecologia Y Piscicultura de Águas Dulces. Madri: Mundi-Prensa. 365p.

BOYD, C.E. 1997. Manejo do solo e da qualidade da água em viveiro para aquicultura. Campinas: Associação Americana de Soja. 55p.

CASTAGNOLLI, N. 1986. Piscicultura nos trópicos. São Paulo: Manole. 152p.

CASTAGNOLli, N. 1992. Piscicultura de água doce. Jaboticabal: Funep. 189p.

CORREDOR, G.G., HENATO, A.R.1982. Monocultivo e policultivo de tilápia nilotica y carpa "Espejo", alimentadas com concentrado comercial para gallinas ponederas. Inf. Téc., (3):47-51.

GRAEFF, A. 1994. Efeito de duas densidades de estocagem no desenvolvimento do fingerlings (Cyprinus carpio, var specularis) em caixas de amnianto. In: SIMPÓSIO BRASILEIRO AQUICULTURA, 8, e ENCONTRO BRASILEIRO DE PATOLOGIAS DE ORGANISMOS AQUÁTICOS, 3, Piracicaba, 1994. Resumos... Piracicaba: FEALQ. p.12.

GRAEFF, A. 1997. Efeito da densidade de povoamento, na produtividade final em carpas (Cyprinus carpio var. specularis) em fase de engorda. 1. Período: inverno. $R$. Soc. Bras. Zootec., 26(3):423-428.

HENAO, A.R., BOLAÑOS, M.,M.A. 1982. Ensayo sobre la utilizacion de alimento comercial para gallinas ponederas en el levante de carpa "Espejo". Inf. Téc. (3):37-40.

HUET, M. 1978. Tratado de piscicultura. Madrid: Mundi Prensa. $705 \mathrm{p}$.

LUKOWICZ, M.V. 1982. Intensive carp Cyprinus carpio L. rearing in a farm pond in southern Germany and its effects on. Aquac. Eng., 1(2):121-137.
MAKINOUCHI, S. 1980. Criação de carpa em água parada. Inf. Agrop., 6(67):30-47.

NOMURA, H. 1984. Dicionário dos peixes do Brasil. Brasília: Editerra. 482p.

NATIONAL RESEARCH COUNCIL - NRC. 1993. Nutrient requirements of fish. N.A.P. Washington, D.C.

ORDOG, V., NUNGS, Z.M.P. Sensibilidade de peixes a amônia livre. In: SIMPÓSIO LATINOAMERICANO, 6, e SIMPÓSIO BRASILEIRO DE AQUICULTURA, 5, Florianópolis-SC. Resumos... Florianópolis: ABRAq. p.160-174, 1988.

REID, G.K., WOOD, R.D. 1976. Ecology of Inland waters and stuaries. New York, Van Nostrawd. 217p.

SILVA, J.W.B. 1983a. Resultados de um ensaio sobre criação de carpa espelho, Cyprinus carpio var. specularis, em viveiro do Centro de Pesquisas Ictiologicas do DNOCs (Pente Coste, Ceará, Brasil). B. Téc. DNOCs, 41(1):145-170.

SILVA, J.W.B. 1984b. Resultados de cultivos experimentais da carpa espelho, (Cyprinus carpio, L. 1758 vr specularis) realizados no Centro de Pesquisas Ictiologicas "Rodolpho Von Ihering”. B. Téc. DNOCs, 42(2):179-211

SZUMIEC, J. 1979. Some experiments in intensive farming of common carp in Poland. In: SZUMIEC, J. (Ed.) Advance in aquaculture. Farnham Surrey: FAO. p.157-161.

WOYNAROVICH E. 1985. Manual de piscicultura. Brasília: MINTER/CODEVASF. 71p.

Recebido em: 12/04/99

Aceito em: 18/12/99 